\title{
Black cluster and cloudy nanoinclusions in the core of Yakutian diamonds: TEM investigation
}

\author{
A.M. Logvinova ${ }^{1}$, R. Wirth ${ }^{2}$ and N.V. Sobolev ${ }^{1}$ \\ ${ }^{1}$ Institute of Geology and Mineralogy, Siberian Branch of Russian Academy of Science, Novosibirsk, Russia \\ ${ }^{2}$ GeoForschungsZentrum,Experimental Geochemistry, Potsdam, Germany.
}

\section{Introduction}

The nanoinclusions located in the central areas of diamonds appear to have been trapped during the very earliest stages of diamond growth, and thus provide unique information about the environment in which diamond crystals nucleated and show the processes with mantle fluid participation. Micro-inclusions in cloudy cubic and octahedral diamonds from Zaire, Botswana, South Africa, Brazil, Canada and Siberia carry melts that vary in composition between the hydrous-silicic end-member and the carbonatitic component (Navon et al., 1988, Izraeli et al, 2001; Zedgenizov et al., 2004). Recently, the nanometer-sizes melt/fluid inclusions are composed of multi-phase assemblages, which include solid phases (silicates, oxides, carbonates), brines (halides) and fluid bubbles were found (Klein-BenDavid et al., 2006; Logvinova et al., 2007, 2008).

The mineral assemblages recorded earlier in the black clusters micro-inclusions of Yakutian diamonds indicate that they grew in a reduced environment, with oxygen fugacity controlled by the iron-wustite equilibrium. Nucleation of diamonds occurred in the presence of a fluid or melt, highly enriched in LILE (K, $\mathrm{Ba}, \mathrm{Rb}, \mathrm{Sr})$ and $\operatorname{HFSE}(\mathrm{Nb}, \mathrm{Ti}, \mathrm{Zr})$, which carried immiscible Fe-Ni-sulfide melts, and possibly a carbonatitic component (Bulanova et al., 1998).

Oriented graphite single-crystal inclusions in diamond have been studied in (Glinnemann et al., 2003). The authors assumed that the graphite crystal was formed first and served as a seed for the diamond

Here we present new data on the composition of the central diamond inclusions, using FIB /TEM method.

\section{Methods}

In the present study we investigated the closely spaced black clusters and cloudy nanoinclusions in the centre of the ten Yakutian diamonds (Komsomolskaya, Internatsionalnaya, Mir, Sytykanskaya and Yubileynaya kimberlite pipes). Transmission electron microscopy (TEM) techniques such as electron diffraction, analytical electron microscopy (AEM) including line scan and elemental mapping, electron energy-loss spectroscopy (EELS) and high-resolution electron microscopy (HREM) were applied. TEM foils have been prepared from the central black part of studied diamonds by using the focused ion beam (FIB) technique (Wirth, 2004).

\section{Samples and Results}

Closely spaced black clusters of nanoinclusions (Fig. 1 A, B) have been studied in five Yakutian diamonds. The coated diamond from Komsomolskaya pipe

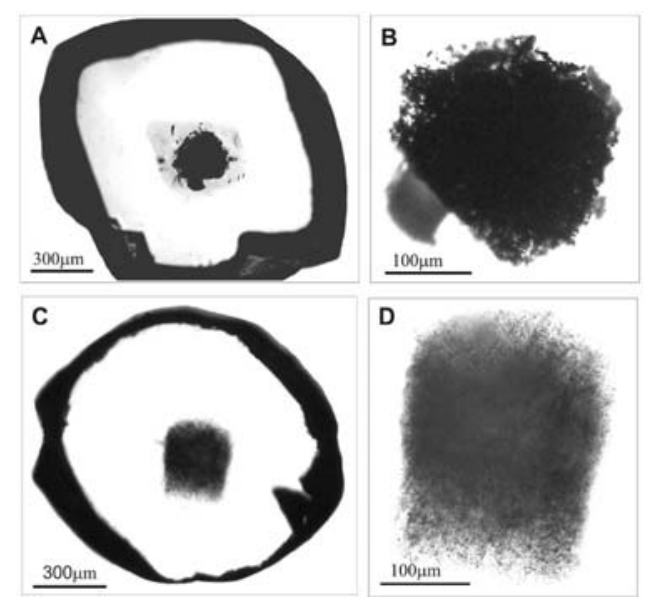

Fig.1. Photomicrographs of diamond plates (A, C) containing nanometer-sized inclusions of black cluster (B) and cloudy (D) central zones.

contains heterogeneous amorphous material, enriched in $\mathrm{F}, \mathrm{O}, \mathrm{Fe}, \mathrm{Mg}, \mathrm{Al}, \mathrm{Si}, \mathrm{Ca}, \mathrm{S}, \mathrm{K}, \mathrm{Cl}$ with a great number of nanocrystals over $10-15 \mathrm{~nm}$ in size and open pores that probably contained volatiles prior to the extraction of the foil. Magnetite, omphacite (high Jdcomponent), sellaite, graphite, periclase and corundum are detected among crystalline phases proved by electron diffraction pattern and chemical composition. Similar inclusion was studied by Bulanova et al. (1998). An EPM analysis gave only bulk composition, including $\mathrm{SiO} 2$, high $\mathrm{FeO}$ content, $\mathrm{MgO}, \mathrm{CaO}, \mathrm{K} 2 \mathrm{O}$, some $\mathrm{Ba}, \mathrm{P}, \mathrm{Cl}$ and in areas of native iron and wustite, small cntents of $\mathrm{Si}, \mathrm{Mg}$ and $\mathrm{Al}$. In addition in Kms174 we found out the quenched $\mathrm{F}, \mathrm{S}, \mathrm{K}, \mathrm{Cl}$-bearing phases. In four octahedral diamond crystals from 


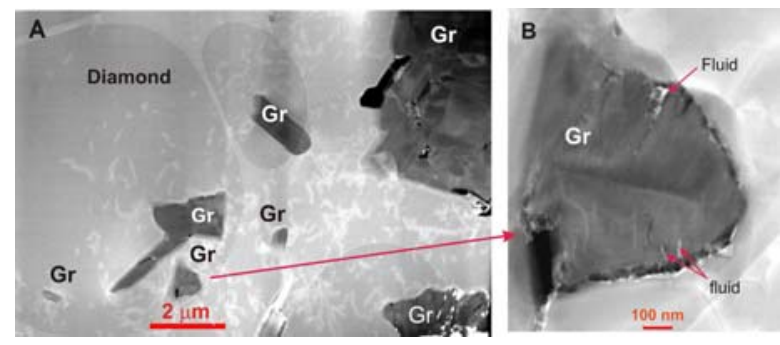

Fig. 2. TEM bright field image of a $0.2 \mathrm{~mm}$ thick foil (A) showing the black cluster zone of Fig. 1A,B with graphite (dark) inclusions and dislocations (white) inside diamond (grey). (B) Enlarged part of (A) with fluid phase inside graphite-inclusion.

Internatsionalnaya, Sytykanskaya and Mir pipes the main crystalline phases in the inclusions were found to be graphite (Fig. 2), which trapped fluid/melt inclusions (silicates, sulfides, magnetite, carbonates and quenched material, enriched in $\mathrm{K}, \mathrm{Cl}, \mathrm{F}, \mathrm{Ba}, \mathrm{Nb}$, $\mathrm{Sr}, \mathrm{Si}, \mathrm{Mg}, \mathrm{O}$ ). These phases are present only in the areas consisting of graphite.

In the sample Im-26 we succeeded in finding the oriented intergrowths of sulfide and graphite (Fig. 3), all of which are homogenous in composition $(\mathrm{Fe} / \mathrm{Ni}$ ratio is constant) and contain fluid bubbles. EDX spectra of these sulfide inclusions (with $\mathrm{Fe}$ contents higher than Ni) show high content of Co. (Fig. 4, 5). This is not observed in large sulfide inclusions extracted from diamonds (Yefimova et al., 1983; Deines and Harris, 1995) and in micrometer-sized sulfide inclusions (Bulanova et al., 1998; KleinBenDavid et al., 2003).
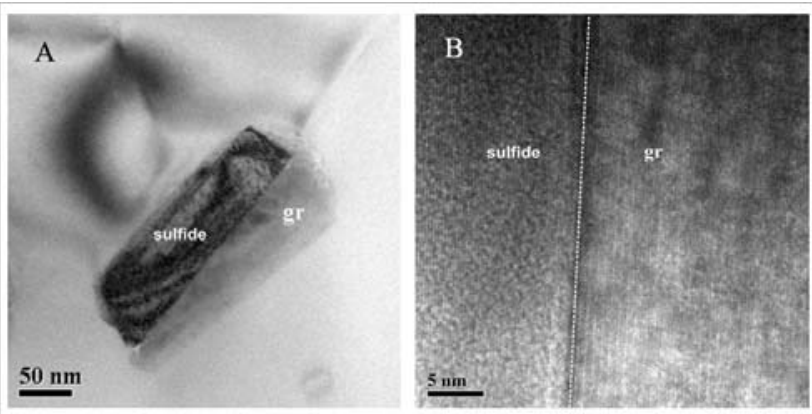

Fig. 3. (A) TEM bright field image of a sulfide - graphite intetgrowth observed in the black cluster. (B) Energy filtered TEM lattice fringe image of sulfide - graphite inclusion. Dotted line marks the boundary between two phases.

Follow the homogenous chemical composition data (Fig. 6) and diffraction pattern we assume, that these sulfide inclusions are the first observation of monosulfide solid solution.
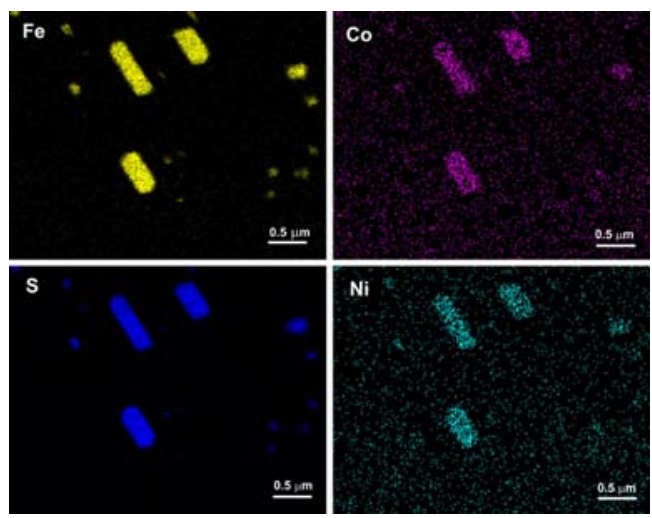

Fig. 4. Element map of nanometer-sized sulfide inclusions inside Internatsionalnaya diamond (sample Im-26) using Fe$\mathrm{K} \alpha, \mathrm{Ni}-\mathrm{K} \alpha, \mathrm{Co}-\mathrm{K} \alpha, \mathrm{S}-\mathrm{K} \alpha \mathrm{X}$-ray intensities.

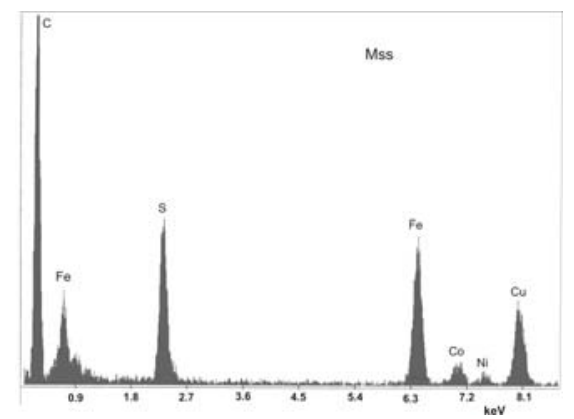

Fig. 5. EDX spectrum from monosulfide (Mss) inclusion. $\mathrm{Cu}$ is present in composition, but we can not produce precise data because of $\mathrm{Cu}$ intensity comes partly from copper grid.

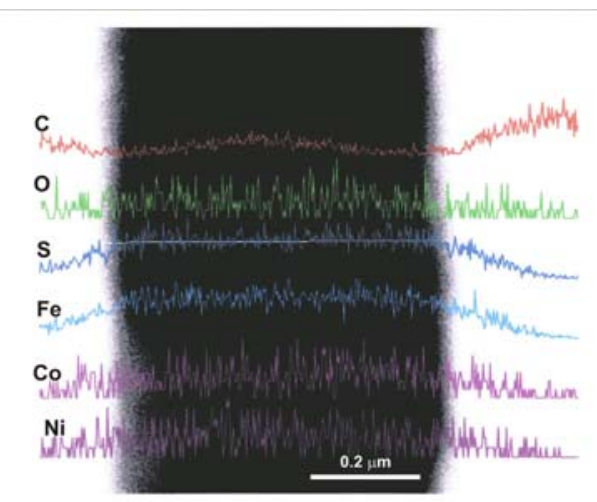

Fig. 6. Line scan across nanometer-sized sulfide inclusion (See Fig.4 A) using Fe-K $\alpha$, Ni-K $\alpha$, Co-K $\alpha$, S$\mathrm{K} \alpha, \mathrm{C}-\mathrm{K} \alpha, \mathrm{O}-\mathrm{K} \alpha$, X-ray intensities.

Over 60 nanoinclusions have been studied in seven cloudy diamonds (Fig. 1 C, D) from Yubileynaya, Udachnaya, Internatsionalnaya pipes. All of them, ranging between 30 and $700 \mathrm{~nm}$ in size, are reflecting the diamond habit and are composed of multi-phase assemblages (Fig. 6) which include silicates, oxides, carbonates, halides, non-crystalline melt material (enriched in K) and fluid bubbles. Phlogopite, Nb-rich ilmenite, apatite, magnetite, clinohumite, dolomite, Ba, Sr- carbonate, periclase, sulfides, kyanite have been established among crystalline mineral phases; the only 
present halide is $\mathrm{KCl}$. Fluid bubbles contain high amounts of K, O and $\mathrm{Cl}$ ( Logvinova et al., 2008).

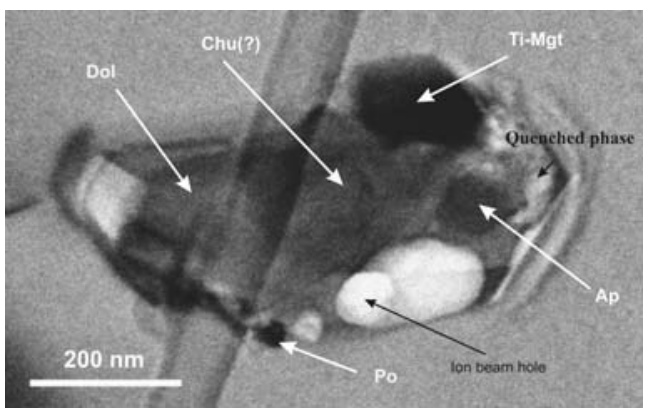

Fig. 7. TEM bright field image of mineral and quenched phases observed within nanometer-sized inclusion from the Internatsionalnaya diamond. The dark line in the background is due to the supporting film.

\section{Conclusion}

The fluid-bearing diamonds grew in the same environment with extremely high K-activity as most other diamonds. Many diamond inclusions exhibit enrichments in incompatible trace elements which are commonly related to interaction with fluids.

The mineral assemblages located in the central zones of Yakutian diamonds indicate that they grew in a reduced environment, with oxygen fugacity controlled by the silicate rich melt, highly enriched in LIL $(\mathrm{K}, \mathrm{Ba}$, $\mathrm{Sr}$ ) and HFSE (Nb, Ti) elements. This fluid also carried a carbonatitic component and immiscible $\mathrm{Cu}-\mathrm{Fe}-\mathrm{Ni}$ sulfide melts, the introduction of fluid into a reduced refractory environment may have been accompanied by a thermal pulse, and may have created the conditions necessary for the nucleation and growth of diamond. The obtained results on complex character and composition of nanoinclusions in diamond testify the significant role of deep metasomatic processes with an involvement of incompatible elements at diamonds formation.

\section{References}

Bulanova, G.P., Griffin, W.L., Ryan, C.G., 1998. Nucleation environment of diamonds from Yakutian kimberlites. Mineral. Magazine, 62(3), 409-419.
Deines, P., Harris, J.W., 1995. Sulfide inclusion chemistry and carbon isotopes of African diamonds. Geochimica et Cosmochimica Acta, 59 (15), 31733188 .

Glinnemann, J., Kusaka, K., Harris, J.W., 2003. Oriented graphite single-crystal inclusions in diamond. $\mathrm{Z}$. Kristallogr., 218, 733-739.

Izraeli, E.S., Harris, J.W., Navon, O., 2001. Brine inclusions in diamonds: a new upper mantle fluid. Earth Planet. Sci. Lett.,187, 323-332.

Klein-BenDavid, O., Logvinova, A.M., Izraeli, E.S., Sobolev, N.V., Navon, O., 2003. Sulfide melt inclusions in Yubileinayan (Yakutia) diamonds. 8IKC, Extended Abstracts, FLA 111.

Klein-BenDavid, O., Wirth, R., Navon, O., 2006. TEM imaging and analysis of microinclusions in diamonds: A close look at diamond-growing fluids. Amer. Mineral., 91, 353-365.

Logvinova, A.M., Zedgenizov, D.A., Sobolev, N.V., 2001. Pyroxenite paragenesis of abundant mineral and probable fluid inclusions in microdiamonds from the Mir kimberlite pipe, Yakutia. Dokl. Earth Sci., 380 (7), 795-799.

Logvinova, A.M., Wirth, R., Fedorova, E.N., Sobolev, N.V., 2008. Nanometer-sized mineral and fluid inclusions in cloudy Siberian diamonds: new insights on diamond formation. Eur. J. Miner., 20 (3), 317-331.

Logvinova, A.M., Wirth, R., Fedorova, E.N., Sobolev, N.V., 2007. Cloudy nano-sized inclusions in Yakutian diamonds: the pecularities of composition and paragenesis. ZRMO, 168 (7), 173-187.

Navon, O., Hutcheon, I.D., Rossman, G.R., Wasserburg, G. J., 1988. Nature, 335, 784-789.

Wirth, R., 2004. Focused Ion Beam (FIB): A novel technology for advanced application of micro- and nanoanalysis in geosciences and applied mineralogy. Eur. J. Mineral., 16, 863-876.

Yefimova, E.S., Sobolev, N.V., Pospelova, L.N., 1983. Sulfide inclusions in diamonds and peculiarities of their paragenesis, ZVMO, CXII (3), 300-310.

Zedgenizov, D.A., Kagi, H., Shatsky, V.S., Sobolev, N.V., 2004. Carbonatitic melts in cuboid diamonds from Udachnaya kimberlite pipe (Yakutia): evidence from vibrational spectroscopy. Mineral. Magazine, 68(1), 61-73. 
